\title{
$614 \cdot 27$ \\ las propiedades de los yesos de moldeo y enlucidos y sus ensayos
}

\section{introducción}

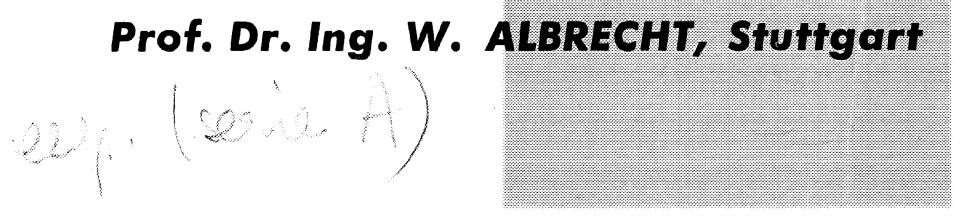

Las discusiones habidas en el seno de las Comisiones técnicas, por ejemplo en las encargadas de redactar las normas, tanto nacionales como internacionales, sobre las propiedades tecnológicas de los yesos, demuestran la necesidad de conocer los fundamentos de la tecnología de los yesos em. pleados en la construcción. La exacta distinción entre las distintas clases de yesos, las normas que deben seguirse para su fabricación y las propiedades que han de caracterizar su empleo, deben establecerse a base de los conocimientos fundamentales.

Tratar de estas generalidades en una asamblea como el EUROGYPSUM, de carácter internacional, me parece muy conveniente por dos razones. La primera es que sobre esas bases fundamentales y con ayuda de esta reunión internacional de los interesados en la industria del yeso podremos llegar a coincidencias que, de hecho, ya existen en muchos puntos. Por otra parte procuraré dar a conocer ciertas particularidades propias de la industria alemana del yeso, con objeto de que los representantes de los otros países tengan ocasión de apreciar las diferencias existentes entre sus industrias y la específica de Alemania. Estas diferencias son debidas a los numerosos hidratos que se producen al calcinar los minerales de yeso, a la variedad de las mezclas de los mismos y a los distintos tipos de hornos y métodos de calcinación que pueden emplearse en cada caso.

Como esta Asamblea se celebra en España, donde los yesos de enlucido tienen especial importancia, me referiré principalmente a esta clase de material, así como también a su análoga de los yesos de moldeo (o de estuco), haciendo referencia, como es natural, a los productos alemanes.

Los conceptos fundamentales de que voy a tratar son conocidos (1), pero no están suficientemente divulgados. No trataré, por lo tanto, de las investigaciones realizadas en las últimas semanas o meses. Sin embargo, creo que esta ponencia interesará a todos los asambleístas. La brevedad de la misma ha hecho necesaria una previa selección de las propiedades de que voy a tratar. Creo que, con ello, satisfaré a los legítimos deseos de los asambleístas.

\section{1. - deshidratación e hidratación}

Para definir nuestros yesos calcinados, especialmente los utilizados en la construción, y conocer sus principales propiedades, expondremos primeramente los fundamentos de la deshidratación (eliminación del agua) y de la hidratación (combinación del producto fabricado con el agua) (véase figura 1). 


\begin{tabular}{|c|c|c|c|c|}
\hline \multicolumn{2}{|c|}{ MATERIAL DE PARTIDA } & \multicolumn{3}{|c|}{$\begin{array}{l}\text { MINERAL DE YESO (ALGEZ) } \\
\text { (YESO CRUDO, DIHIDRATO) }\end{array}$} \\
\hline \multicolumn{2}{|l|}{ DESHIDRATACION } & $\begin{array}{l}\text { CALDERAS } \\
\text { HORNOS ROTATORIOS } \\
\text { Y OTROS }\end{array}$ & $\begin{array}{l}\text { CALCINACION EN } \\
\text { MORNOS DE } \\
\text { CAMARAS } \\
\text { Y OTROS }\end{array}$ & $\begin{array}{l}\text { HORNOS } \\
\text { VERTICALES }\end{array}$ \\
\hline \multicolumn{2}{|c|}{ PRODUCTOS TECNICOS } & YESO DE MOLDEO & $\begin{array}{l}\text { YESO DE } \\
\text { ENLUCIDOS }\end{array}$ & $\begin{array}{l}\text { YESO DE REVOQUE } \\
\text { YESO-MARMOL }\end{array}$ \\
\hline \multicolumn{2}{|c|}{ ESCALA DE HIDRATOS } & $-100 \%$ & 16 & $-100 \%$ \\
\hline$<100^{\circ}$ & DIHIDRATO & & & \\
\hline$>120^{\circ}$ & $\alpha-\beta$ - HEMIHIDRATO & & & \\
\hline$>200^{\circ}$ & $\alpha-, \beta$-ANHIDRITA III & & & \\
\hline $\begin{array}{l}400 / 800^{\circ} \\
<1200^{\circ}\end{array}$ & $\begin{array}{l}\text { ANHIDRITA II } \\
\text { ANHIDRITA I }\end{array}$ & & & \\
\hline \multirow{2}{*}{\multicolumn{2}{|c|}{ HIDRATACION }} & \multicolumn{3}{|c|}{ SIN ACELERADORES } \\
\hline & & RAPIDO & LENTO & MUY LENTO \\
\hline \multicolumn{2}{|c|}{$\begin{array}{l}\text { DEL DIHIDRATO } \\
\text { (SIN ESCALONES INTERMEDIOS) }\end{array}$} & \multicolumn{3}{|c|}{$\begin{array}{l}\text { RETARDADO P.G. CON ALBUMINA } \\
\text { ACELERADO P.G. CON DIHIDRATO }\end{array}$} \\
\hline \multirow{2}{*}{\multicolumn{2}{|c|}{ POST-HIDRATACION }} & \multicolumn{3}{|c|}{ CON EXPANSION $(1$ A $3 \mathrm{~mm} / \mathrm{m})$} \\
\hline & & NO & SENSIBLEMENTE & PERO SIN SER \\
\hline
\end{tabular}

Fig. 1. Deshidratoción e hidratación de los yesos de construcción

La deshidratación del mineral de partida: sulfato de calcio hidratado (llamado piedra de yeso o algez) hecha en calderas, hornos rotatorios, hornos de pisos superpuestos e instalaciones de molturación da un producto que llamaremos yeso de moldeo, compuesto principalmente de hemihidrato $\beta$. Esta clase de yeso se utilizaba antiguamente con preferencia para revoques de estuco; actualmente, su empleo más corriente es para la fabricación de piezas (por ejemplo, placas de yeso), y además como adición a los morteros de cal (para enlucidos interiores). El nombre de yeso de estuco empleado en Alemania no corresponde ya a su utilización más corriente, aunque es el que generalmente se usa. En autoclaves se fabrican yesos especiales de alta calidad (hemihidrato $\alpha$ ), que tienen analogía con los yesos de moldeo. Los diversos hornos y métodos de calcinación dan yesos que poseen propiedades peculiares, pero no entraremos en su estudio.

En los hornos de cámaras, en los superpuestos o de pisos y en los de parrilla móvil se fabrican los yesos para enlucidos que, con arena o sin ella, se emplean en los enlucidos interiores de edificios.

En los hornos verticales se fabrican los yesos para enfoscados y revoques, y también, con un tratamiento previo, el llamado yeso de mármol.

En los distintos tipos de hornos (2) se obtienen los diversos hidratos que corresponden a las temperaturas indicadas en la figura 1. En las calderas, hornos rotatorios e instalaciones similares se produce principalmente el hemihidrato $\beta$, que es poroso, junto con una pequeña cantidad de anhidrita III, soluble. En las autoclaves se produce el hemihidrato $\alpha$, que es compacto. En los hornos de cámaras y análogos resultan como productos el hemihidrato $\beta$ y la anhidrita III, junto con cantidades considerables de anhidrita II. En el núcleo de los hornos de cámaras, los trozos gruesos de 
mineral introducidos en el horno quedan sin calcinar y contienen el dihidrato corriente o yeso crudo. Una parte de los yesos de enlucidos, después de la calcinación en el horno, suelen someterse a una segunda calcinación en caldera: se dice entonces que el yeso es de doble calcinación. Estos yesos no contienen ya sulfato cálcico hidratado y, por lo tanto, su composición es más regular que la de los yesos de calcinación única procedentes de los hornos de cámaras. En los hornos verticales, la deshidratación es completa: se forman así anhidritas II y $I$.

Los contenidos en hidratos de los distintos yesos, señalados en la figura 1, deben considerarse solamente como valores de orientación. Las proporciones exactas varían según el tipo de horno y régimen de fabricación.

Los productos fabricados (yeso de moldeo, de enlucidos, etc.) amasados con agua se combinan con ella (hidratación), formándose de nuevo el hidrato doble, en todos los casos, sin que resulten productos intermedios. En oposición a lo que ocurre con las anhidritas naturales o con las de residuos industriales (anhidritas sintéticas), los yesos calcinados corrientes no necesitan activadores para su hidratación. Sin embargo, en los yesos de enlucidos de calcinación simple, el pequeño contenido del hidrato doble (yeso natural) actúa como activador, no de la hidratación, sino de la cristalización; en el yeso de enfoscados desempeña idéntico papel la pequeña cantidad de cal libre que se forma.

La hidratación del yeso de moldeo (hemihidrato) es rápida (generalmente media hora). En el yeso de enlucidos, al principio es rápida, pero luego se hace más lenta que en el yeso de moldeo; en el yeso de revoque o enfoscado y en el marmóreo es aún más lenta. Con la hidratación se pro-

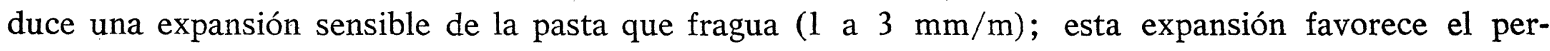
fecto relleno de la pasta en los moldes. La ya citada rápida expansión es una propiedad muy ventajosa, característica de los yesos. El proceso de hidratación es regulable dentro de ciertos límites. En los yesos de moldear conviene a veces un retraso en este proceso. Como sustancias retardadoras actúan algunas materias orgánicas, por ejemplo, los residuos derivados de la albúmina. La aceleración del proceso de hidratación se consigue, entre otros medios, añadiendo un poco de yeso dihidratado (yeso natural, sin calcinar).

Con la hidratación rápida del yeso de moldeo se elimina por completo el proceso de hidratación ulterior (posthidratación), es decir, la hidratación lenta que tiene lugar por la conservación o exposición en ambiente húmedo. El grado de intensidad de la posthidratación de las otras clases de yeso depende del contenido de anhidritas II y I.

La posthidratación de los yesos de enlucidos es preciso tenerla muy en cuenta, porque en presencia del agua libre (por ejemplo, exceso de agua en los elementos fabricados) se produce un aumento sensible de resistencia final. Este aumento de resistencia de los yesos de enlucidos, conservados durante siete días en ambiente húmedo, puede llegar hasta el 30 por 100. Esa conservación durante varios días es la que, de un modo natural, se establece al extender los enlucidos, gracias a la humedad natural del ambiente exterior. En las normas oficiales alemanas antiguas (DIN 1168, hoja 2, n. ${ }^{\circ} 272$ ) se exigía como prueba la conservación de probetas durante siete días en ambiente húmedo. En las anhidritas no preparadas por calcinación (anhidritas naturales y sintéticas), la posthidratación, en ciertas condiciones, puede dar lugar a una expansión excesiva (hasta la disgregación) de los objetos de yeso una vez endurecidos. En cambio, en los yesos fabricados por calcinación la posthidratación de las anhidritas II y I no produce expansión nociva. Como se ha dicho ya, incluso pueden observarse aumentos de resistencia. 


\section{2. - el fraguado}

El fraguado de los yesos de moldeo y de enlucidos queda completado en el transcurso de 20 a 30 minutos, contados a partir del amasado. El fraguado es un cambio de consistencia debido a la formación de un entramado o esqueleto de cristales, bastante denso, en el interior de la masa. El fraguado se puede medir unos pocos minutos después de efectuado el amasado mediante el ensayo de dureza, utilizando pequeñas sobrecargas. En la figura 2 la dureza, o sea la resistencia, se da en función del tiempo transcurrido desde que se efectuó el amasado. El principio o comienzo del fraguado es el instante en que la pasta deja de ser líquida. Es también el instante en que comienza la trabajabilidad (moldeo, extensión) del material; en la figura 2 está señalado por la línea de rayas y puntos. Al aumentar la resistencia se llega al final del fraguado (línea de puntos seguidos). El lapso de tiempo que transcurre hasta el final del fraguado es dos y media a tres veces el del comienzo del mismo (véanse los ejemplos en la fig. 2: en el yeso de enlucido, principio 4 min, final $12 \mathrm{~min}$; en el yeso de moldeo, principio $8 \mathrm{~min}$, final $20 \mathrm{~min}$ ). Más tarde la masa fraguada es tan sólida que no puede deformarse con los medios de trabajo ordinarios. Se alcanza así el final del tiempo de trabajabilidad (línea de trazos, fig. 2).

¿Qué diferencia hay entre los yesos de moldeo y los de enlucidos en estos procesos de fraguado y trabajabilidad?

El yeso de moldeo necesita un pequeño intervalo de tiempo para que los hemihidratos se incorporen a la solución y se formen los primeros cristales del hidrato doble. A continuación, la formación de más cristales sigue muy rápidamente. Como el yeso de moldeo tiene una composición bastante uniforme en hemihidratos, el proceso de hidratación se desarrolla con rapidez. Simultáneamente se desarrolla el aumento de resistencia hasta que se llega al límite de trabajabilidad del material. Un yeso de esta clase (es decir, de moldeo) empleado como conglomerante de mortero es trabajable durante un tiempo muy corto (en el ejemplo de la fig. 2, unos 16 minutos), ya que el aumento de resistencia tiene lugar también rápidamente.

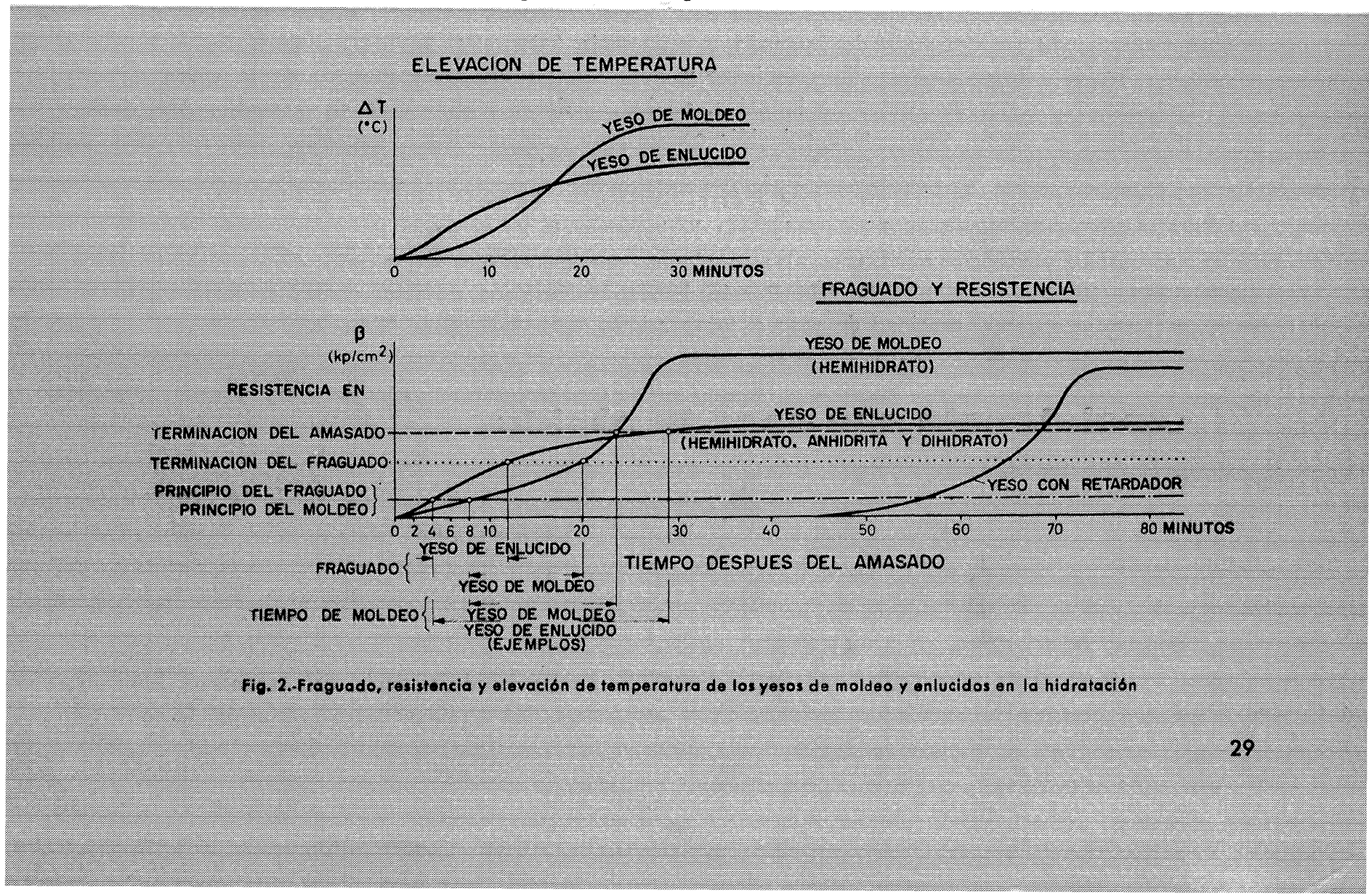


El yeso de enlucidos tiene para comenzar el fraguado un tiempo más corto (es decir, empieza a fraguar antes) porque contiene cierta cantidad de hidrato doble como germen de cristalización. La segunda parte de la hidratación (la posthidratación) no se desarrolla tan rápidamente como la primera (hasta el final del fraguado) porque la hidratación de las anhidritas II y I va más lenta. Por lo tanto, la pasta del yeso de enlucidos que va espesándose es trabajable durante más largo tiempo que la del yeso de moldeo (en el ejemplo de la fig. 2, unos 25 minutos). La presencia de los tres escalones de hidratos trae como consecuencia una hidratación que comienza más pronto y se desarrolla luego con mayor lentitud, por todo lo cual el tiempo de duración de la trabajabilidad es mayor.

Cuando termina la hidratación de los yesos se alcanza el primer escalón de resistencia. Esta se llama “resistencia húmeda». En general, para el yeso de enlucido es menor que para el de moldeo, debido a que la pureza del mineral de partida es casi siempre menor para la fabricación del yeso de enlucidos que para el de moldeo. Sin embargo, la resistencia del yeso de enlucidos y del de revoque sigue aumentando en la posthidratación (lo cual no puede verse en la fig. 2) porque la escala de tiempos llega sólo hasta 80 minutos.

Si se mezcla el yeso de moldeo con un material retardador, la curva de fraguado queda corrida en un cierto intervalo (que puede llegar a ser de varias horas). Esta prolongación del tiempo de fraguado influye en la forma de los cristales del hidrato doble, que quedan algo aplastados. Y esto, a su vez, produce una cierta disminución de la resistencia del yeso como se ve en la fig. .2

\section{3. - calor de hidratación}

La hidratación va acompañada siempre de elevación de temperatura (o sea, que se produce desprendimiento de calor). La energía térmica que fue necesaria para expulsar el agua de los minerales en el proceso de calcinación se libera en el de hidratación. La curva de temperaturas presenta una marcha análoga a la de fraguado o resistencia (véase fig. 2). Sin embargo, no es posible señalar los tiempos de fraguado (comienzo y final) en puntos característicos de la curva de temperaturas, p. ej. en los puntos de inflexión, en los máximos o en los de valor medio. Así, el final del fraguado en un yeso puede coincidir con el punto máximo de la curva de temperaturas; la de otro yeso puede caer a media altura. Es evidente que las características de fraguado deben determinarse por ensayos directos (véase más adelante núm. 8), pero nunca deducirlas de la curva de temperaturas. No por eso debe desdeñarse la importancia de la curva de temperaturas, puesto que su marcha $\mathrm{y}$ aspecto pueden señalarnos algunas particularidades interesantes de los yesos (por ejemplo, su contenido en anhidrita III). Por lo demás, la elevación de temperatura en probetas $u$ objetos que tienen igual cantidad de yeso es proporcional a la resistencia húmeda.

\section{4. - resistencia con secado rápido}

Si se seca rápidamente una probeta de yeso, por ejemplo en un horno a $40^{\circ} \mathrm{C}$ de temperatura, al principio la resistencia no aumenta de un modo esencial (véase fig. 3). Pero cuando la humedad desciende a un reducido tanto por ciento (cuando la probeta pasa del color gris al blanco), la elevación de resistencia es muy sensible. La resistencia aumenta, en este caso, hasta alcanzar $2 \frac{1}{2}$ a 3 veces el valor de la resistencia húmeda. Por lo tanto, en el yeso la resistencia no es proporcional al contenido de humedad. Examinando las curvas, se reconoce fácilmente que a pequeñas variaciones de humedad, dentro del estado bajo de humedad (es decir, con menos de $1 \%$ de agua), corresponden grandes variaciones en la resistencia. Por ejemplo: a una variación de con- 
tenido de agua en la probeta de solamente $0,1 \%$, corresponde una variación de la resistencia del $8 \%$. La resistencia seca sólo tiene sentido considerando las condiciones del ambiente.

Hemos de recordar también que el contenido de humedad de la probeta u objeto, tanto si se seca al aire como si se seca en un ambiente determinado, acaba por acomodarse a las condiciones de dicho ambiente; es decir, que a una determinada humedad relativa, p. ej. del aire, acaba por corresponder otra humedad también perfectamente determinada de la probeta. No es, por tanto, admisible creer que una probeta u objeto de yeso que esté seco permanezca ya seco en lo sucesivo. El yeso, lo mismo que la madera y muchos otros materiales, posee un equilibrio higroscópico.

\section{5. - Ia resistencia con secado lento}

Con el secado natural, p. ej., en locales cubiertos, la duración del mismo es bastante larga. Depende de la humedad relativa del aire, de su temperatura, de su movimiento, de las dimensiones y forma de la probeta $\mathrm{u}$ objeto de yeso de que se trate y puede durar días o semanas. Es frecuente que durante las primeras horas o días se pueda comprobar un retroceso o disminución de la resistencia húmeda que puede llegar a valer del 10 al $20 \%$. Este proceso se explica por la modificación que experimentan los cristales del dihidrato (3); la tensión de disolución redondea los vértices de los cristales y se deposita yeso en las caras laterales. Quedan así los cristales aplastados y, como consecuencia, la resistencia disminuye. Observando esta regresión en la resistencia al extender un enlucido, en el instante más desfavorable puede surgir el temor de que dicho enlucido se reblandezca en exceso y se desprenda de la pared. Dicho temor es infundado, y la calidad del enlucido queda inalterable porque el estado húmedo es transitorio; y el propio efecto de la humedad en el proceso ya conocido, y que hemos llamado de posthidratación, llega a superar la regresión resultando, en definitiva, que la resistencia final es superior a la que tenía el material antes de la regresión. Si ponemos la resistencia del yeso de enlucidos con secado rápido igual a $100 \%$, la resistencia final con secado lento, a pesar de la regresión, es de 100 a $130 \%$ (véase fig. 3).

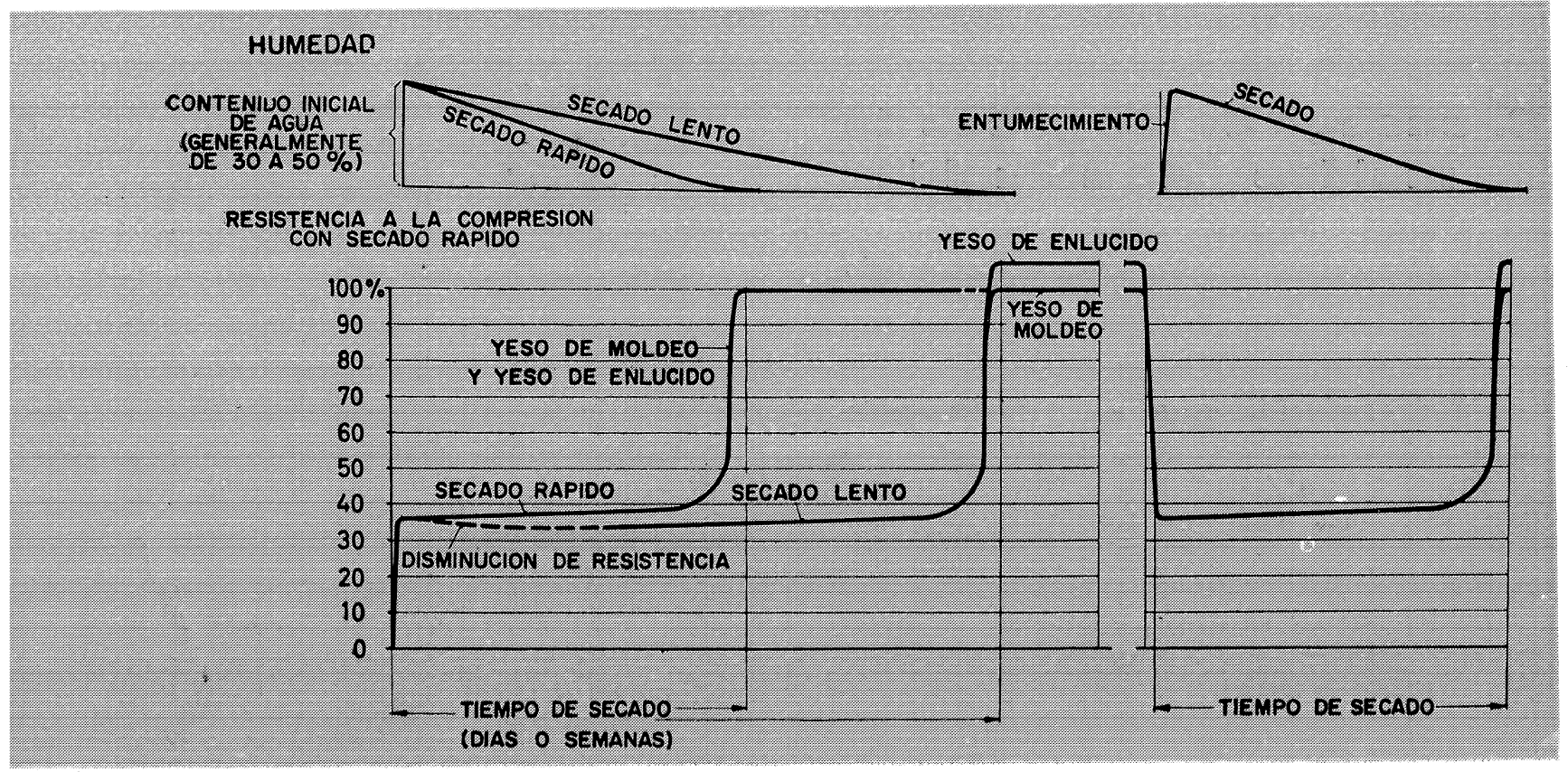

Fig. 3.-Resistencia con secado y entumecimiento del yeso 


\section{6. - la resistencia con entumecimiento de las piezas}

Si una probeta o un objeto de yeso se humedece, la resistencia se reduçe hasta el valor de la resistencia húmeda que, según la figura 3, oscila del 35 al $40 \%$ de la «resistencia seca». Esta regresión, más que a una transformación química, por ejemplo, un cambio de cristalización, debe atribuirse a un efecto físico. Dentro de la masa de yeso, el ambiente es acuoso y los cristales resbalan con mayor facilidad. La resistencia contra la acción de fuerzas o causas exteriores es menor. Al secarse las piezas, la resistencia recupera su valor primitivo.

\section{7. - interpretación de los valores de la resistencia}

Hemos de recordar, ahora, la sencilla relación que existe entre la resistencia a la compresión $\sigma_{\mathrm{d}}(1) \mathrm{y}$ el valor $\mathrm{w}$ de la llamada «relación agua/yeso» ( $\mathrm{w}=$ agua/yeso, ambos en peso, empleados para confeccionar la pasta). Esa relación, como se ve en la figura 4, viene representada por una hipérbola de constante $Q$. Todo yeso tiene su constante característica $Q$; así por ejemplo, el yeso 1 tiene la constante $\mathrm{Q}=53 \mathrm{~kg} / \mathrm{cm}^{2}$. Los valores de $Q$ en los yesos de moldeo alemanes están comprendidos entre 40 y $80 \mathrm{~kg} / \mathrm{cm}^{2}$; los de enlucido, entre 25 y $60 \mathrm{~kg} / \mathrm{cm}^{2}$. En el yeso $1 \mathrm{con} \mathrm{Q}=53 \mathrm{~kg} /$ centímetro cuadrado, la ecuación que se da en la figura 4 , o sea, $\sigma_{d}=\mathrm{Q} / \mathrm{w}^{2}$ nos da por resultado:

$$
\begin{aligned}
& \text { para } \mathrm{w}=0,6 \text { una resistencia a compresión de } 53 / 0,36=147 \mathrm{~kg} / \mathrm{cm}^{2} \\
& \text { para } \mathrm{w}=0,8 \text { una resistencia a compresión de } 53 / 0,64=83 \mathrm{~kg} / \mathrm{cm}^{2} \\
& \text { para } \mathrm{w}=1,0 \text { una resistencia a compresión de }=53 \mathrm{~kg} / \mathrm{cm}^{2}
\end{aligned}
$$

Y por lo tanto, como se deduce tanto del diagrama como de la ecuación, $Q$, se puede definir como la resistencia a la compresión del yeso cuando la relación agua/yeso $\mathrm{w}=1$ (iguales cantidades en peso de agua y yeso para formar la pasta). La resistencia a la compresión puede deducirse fácilmente para cualquier valor de la relación agua/yeso siempre que sea conocido el valor de uno de ellos.

\section{B.-ensayo de los yesos de moldeo y de enlucidos}

Para los ensayos debe tenerse en cuenta todo lo que se indica a continuación :

\section{1. - relación agua/yeso de la pasta}

El factor agua/yeso, o sea, la relación en peso (agua/yeso) tiene influencia decisiva en los resultados de los ensayos de fraguado y de resistencia.

En las normas alemanas, en vez de la característica “relación agua/yeso w», se suele emplear

(1) Actualmente se designa con $\beta_{\mathrm{d}}$.

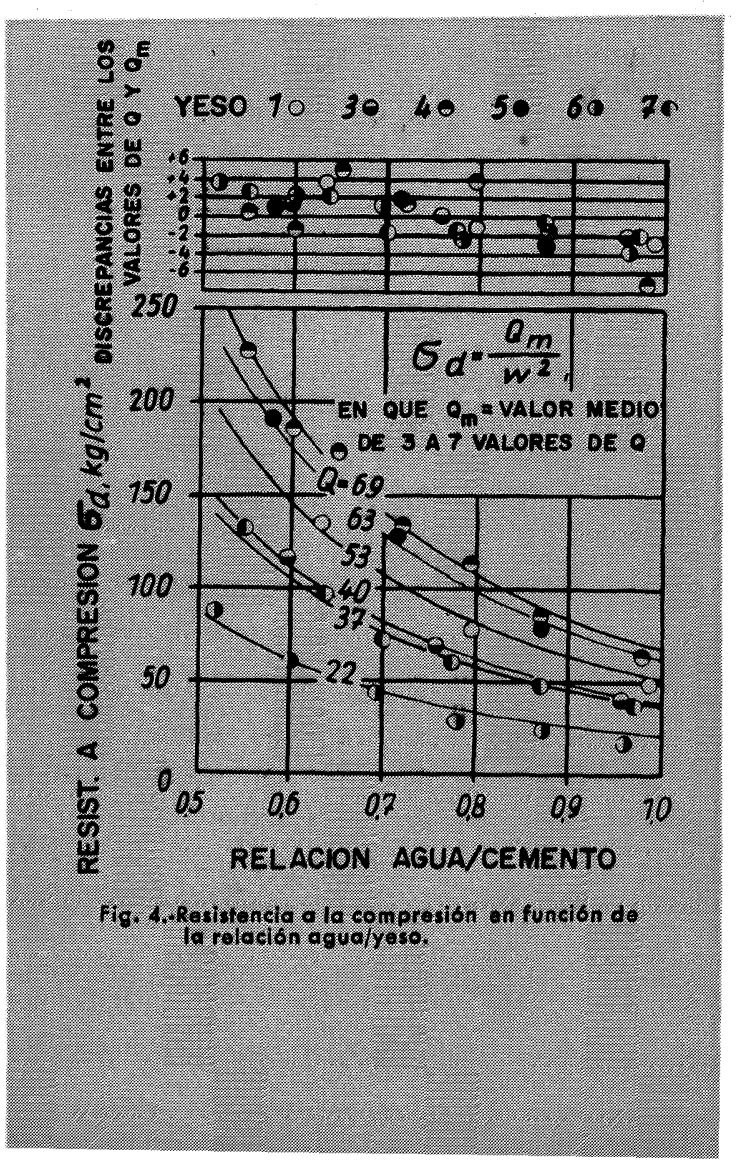


100

la llamada "cantidad específica de conglomerante E» (definida por $\mathrm{w}=\frac{-}{\mathrm{E}}$, en que $\mathrm{E}$ es la cantidad de yeso (en g) que, para confeccionar la pasta, se incorpora a cada $100 \mathrm{~g}$ de agua).

Se han expuesto siempre opiniones de si conviene utilizar la característica w o la $E$; esta última es la que ha prevalecido en Alemania durante más de 6 decenios.

A favor del empleo de la segunda opinión está el que conviene confeccionar las probetas de ensayo con pastas de igual consistencia. La consistencia más apropiada es la que mejor se acomode a la densidad "natural» de distribución de las partículas de yeso en el agua, aunque las pastas de partida no tengan la misma relación agua/yeso. Esto mismo se aplica a otros conglomerantes, por ejemplo, a las cales, según DIN 1060. La mayor o menor afinidad con el agua (facilidad o dificultad de mojarse) se refleja en el resultado de los ensayos. Así por ejemplo, los yesos se mojan con dificultad y por eso conviene que las pastas tengan exceso de agua (con lo que disminuye la resistencia de las probetas); esto mismo es aplicable a otros conglomerantes. Con la pasta confeccionada a base del coeficiente $E$, se tiene la garantía de que posee la consistencia adecuada para los ensayos. En la práctica, la consistencia adecuada tiene importancia: si la pasta es demasiado espesa es fácil dar a las. probetas el tamaño conveniente, pero existe el peligro de que los moldes no se llenen bien y queden huecos o burbujas en el interior. Por el contrario, si la pasta es muy líquida (poca consistencia) se llenan muy bien los moldes, pero resultan probetas de escasa resistencia en los ensayos y, como consecuencia de esto, se producen errores al trasladar el resultado a probetas confeccionadas con menor cantidad de agua. A favor del método tenemos, además, que en el empleo de los yesos de moldeo y enlucidos la cantidad de yeso suele darse con arreglo a la característica $E$.

Este método de la "cantidad específica de conglomerante» es el que se detalla en la norma DIN 1168 (marzo 1955) y, de hecho, las divergencias de esas "cantidades específicas de conglomerantè de un yeso en los diversos laboratorios son relativamente pequeñas. El posible error en la apreciación de esas cantidades es pequeño. Respecto a la exactitud del método, no existen dudas.

En contra del método de las «cantidades específicas de conglomerante» puede decirse que existen numerosas aplicaciones del yeso en que la consistencia espesa de la pasta no desempeña ningún papel, por ejemplo para fabricar objetos cuya pasta ha de ser lo suficientemente flúida para que se adapte a todas las sinuosidades y detalles del molde o, asimismo, cuando se incorpora una cantidad constante de yeso a un mortero de cal. En estos casos solamente interesa la resistencia que puede alcanzarse por incorporación de una determinada cantidad de yeso, y claro está que entonces los ensayos han de orientarse a base de contenido igual de yeso (o sea, empleando la relación agua/yeso), como se practica en diversos países.

Cuando en un país las “cantidades específicas de yeso» difieren poco entre sí, esta cuestión (la de cuál método es preferible) carece de importancia. Las consistencias de las pastas empleadas también se diferencian poco entre sí. En estos casos no hay inconveniente en adoptar un valor fijo para la relación agua/cemento (p. ej. $w=0,8$ ). En la República Federal Alemana las "cantidades específicas de yeson varían entre $\mathrm{E}=110$ a $200 \mathrm{~g}$, que corresponden a valores de la relación agua/yeso $\mathrm{w}=0,9$ a 0,5 . Hasta ahora no hemos visto posibilidad ni necesidad de recomendar el empleo de un valor fijo de w para materiales que tienen tan diversas características de $E$.

Debe quedar perfectamente claro lo siguiente: los resultados de los ensayos efectuados con ambos métodos (“cantidades específicas» y relación agua/yeso) pueden ser distintos. El primer método se emplea con yesos bastos que necesitan grandes cantidades de material para formar pasta que proporcionen probetas de suficiente tamaño y gran resistencia. El segundo método (relación agua/yeso) se utiliza cuando los yesos son finos y sólo necesitan poco material para formar la pasta. Como la resistencia de las probetas de ensayo varía con el cuadrado del valor del «factor agua/yeso w w (véanse 
las fórmulas de la fig. 4), la diferencia entre ambos métodos es considerable. La modificación de las normas no deberá hacerse hasta pesar bien las ventajas e inconvenientes de ambos métodos.

Mientras exista la discusión, queda como recurso determinar las resistencias obtenidas por uno de los métodos en función de las obtenidas con el otro, mediante la relación que ya conocemos. Por ejemplo: el yeso I con $\mathrm{w}=0,8$ nos da como resistencia a la compresión $\sigma_{\mathrm{d}}=83 \mathrm{~kg} / \mathrm{cm}^{2}$; de aquí se deduce que $\mathrm{Q}=53 \mathrm{~kg} / \mathrm{cm}^{2}$. El yeso II con $\mathrm{w}=0,6$ nos da en el ensayo $\sigma_{\mathrm{d}}=111 \mathrm{~kg} / \mathrm{cm}^{2}$; de donde $\mathrm{Q}=40 \mathrm{~kg} / \mathrm{cm}^{2}$. Como el valor de $Q$ del primer yeso es mayor que el del segundo, deducimos que, para el mismo contenido de yeso (método 2), el I es más resistente que el II. En cambio, si se comparan solamente las resistencias que dan directamente los ensayos $\left(83 \mathrm{y} 111 \mathrm{~kg} / \mathrm{cm}^{2}\right)$, el yeso II es mejor (más resistente).

\section{2. - ensayo de fraguado}

Debemos advertir expresamente que los métodos que acabamos de describir no sirven para ensayar yesos a los que se hayan mezclado sustancias retardadoras del fraguado. En estos yesos, la larga duración del estado plástico produce una separación de la mezcla que impide llegar a un estado determinado propio para el ensayo. Estos yesos deben ensayarse con pastas que tengan poca cantidad de agua y según métodos ideados en Norteamérica e Inglaterra. En la República Federal Alemana existe actualmente un proyecto de normas para su ensayo (DIN 1168; hoja 3; proyecto de octubre 1960).

El comienzo del fraguado de los yesos de moldeo y de enlucido se hace cortando la probeta de ensayo con un cuchillo: el ensayo es de gran precisión. Lo importante es determinar el instante preciso en que los bordes del corte se sostienen (véase fig. 5). Nuestros intentos de ensayo con la aguja de Vicat no condujeron a resultados satisfactorios, ya que, con algunos yesos, los bordes se llenaban con espuma de la pasta tan rápidamente que no era posible la fijación exacta del instante en que los mencionados bordes permanecían estables.

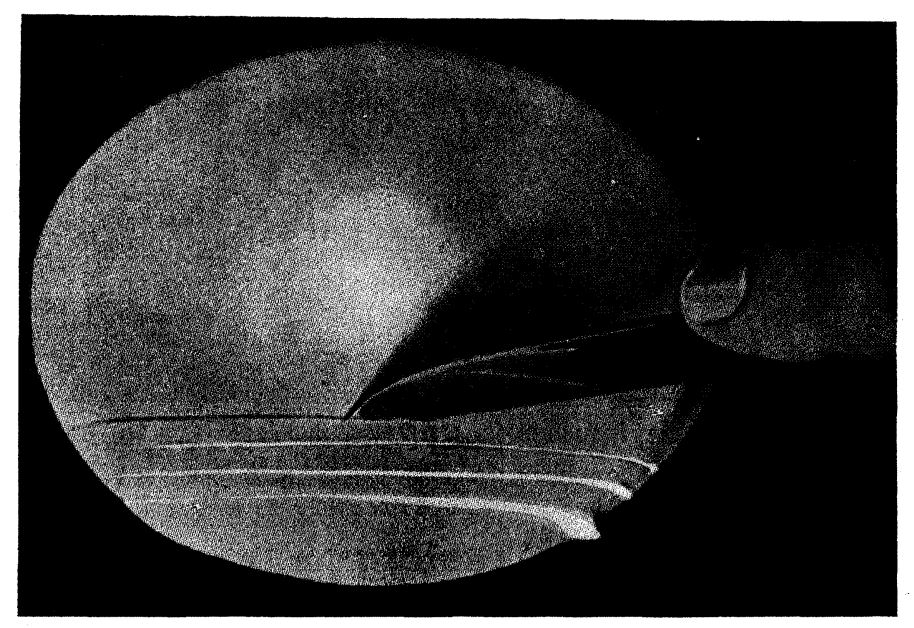

Fig. 5 -Determinación del comienzo del fraguado

La terminación del fraguado se fija en las normas francesas y alemanas para yesos, en el instante en que la presión de la yema de un dedo sobre la probeta no produce huella apreciable (véase figura 6). El método de ensayo resulta muy sencillo y es eficaz. Los cristales del dihidrato forman con rapidez un entramado resistente que soporta bien la acción de la presión, de tal manera que las pequeñas diferencias de presión que pueden aplicarse $(5 \pm 1 \mathrm{~kg})$ no influyen en el resultado: La efi- 
cacia práctica del método se ha puesto en duda con cierta frecuencia. Sin embargo, no existe motivo para ello. No debe creerse que la exactitud de un método de ensayo ha de juzgarse por el precio de los aparatos de ensayo ni por la pequeñez de los números obtenidos, que dan la sensación de una precisión que no existe en la realidad. $\mathrm{Si}$, por ejemplo, consideramos la aguja de Vicat, su sección es $1 \mathrm{~mm}^{2}$ y la profundidad que señala el fin del fraguado es de $1 \mathrm{~mm}$. Pues bien, a pesar de la peque-

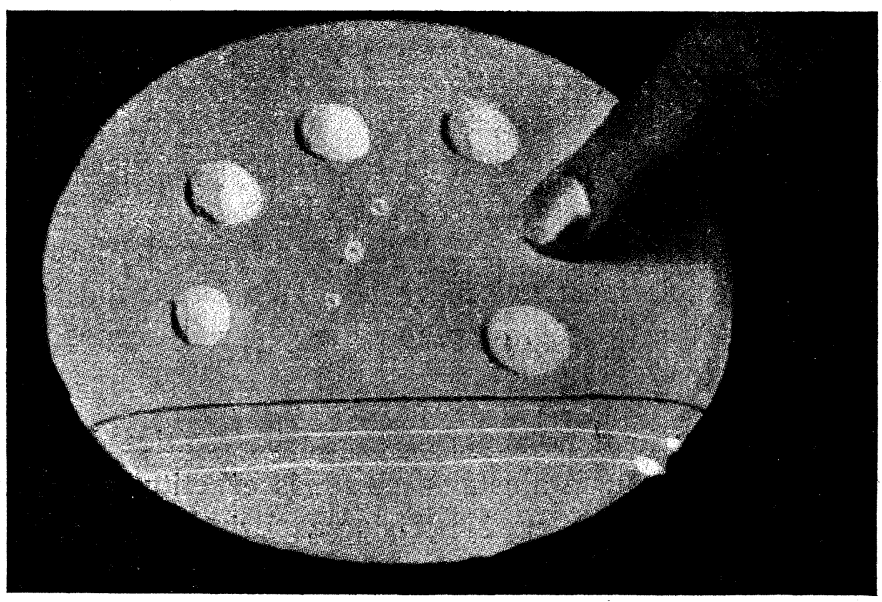

Fig. 6.-Determinación del final del fraguado

ñez de los números, no puede asegurarse que el método tenga una precisión especial. La falta de homogeneidad del material de la probeta de ensayo es tan grande que cada $\mathrm{mm}^{2}$ de superficie de la misma tiene distinta dureza. Convence más elegir una superficie mayor, por ejemplo la de la yema de un dedo. La pretendida exactitud de la aguja de Vicat es, pues, una ilusión según nuestro modo de ver las cosas.

\section{3. - conservación de las piezas, antes del ensayo de resistencia}

En DIN 1168, hoja 2, se prescribe para la conservación de las probetas de yeso, antes de someterlas al ensayo de resistencia, su conservación en un armario-secadero a una temperatura de 35 a $40^{\circ} \mathrm{C}$, o también, para ahorrar gastos de calefacción e instalación, la conservación en un local con 18 a $40^{\circ} \mathrm{C}$ y con un $70 \%$ máximo de humedad relativa del ambiente; a continuación, se ha de hacer un secado final de dos días a la temperatura de 35 a $40^{\circ} \mathrm{C}$. Con ambos procedimientos parece que se obtiene el mismo resultado, ya que las probetas de yeso inmediatamente antes del ensayo han estado sometidas a las mismas condiciones.

El secado con temperatura elevada era antes el preferido porque así șe acortaba la duración del secado y, por tanto, el tiempo invertido en los ensayos. No se señalaban entonces normas referentes a la humedad relativa del aire. El grado de secado en los hornos que se utilizaban con este fin (hornos con corriente de aire o sin ella, con alimentación intensa o débil, con grandes o pequeñas caídas de temperatura) era muy variado e irregular. Aún, con las prescripciones actuales, siempre es de temer que, a pesar de mantenerse la temperatura entre los límites fijados ( 35 a $40^{\circ} \mathrm{C}$ ), reúnen condiciones distintas de humedad relativa en las diversas zonas del mismo horno o de otros similares.

Con Ios avances de la técnica de climatización (acondicionamiento del aire) será, sin duda, posible conseguir una conservación en condiciones perfectamente definidas y regulables, manteniéndose, 
por ejemplo, una temperatura de $20^{\circ} \mathrm{C}$ en un ambiente de humedad relativa de $65 \%$. Ya dijimos, anteriormente, que las diferencias de humedad producen efectos muy sensibles y así basta una diferencia de $0,1 \%$ en el grado de humedad relativa para producir en la resistencia una variación del $8 \%$. A nuestro juicio, las condiciones de conservación deben fijarse con normas más precisas y uniformes que las señaladas hasta ahora. La repetición de los ensayos con las normas actuales deja bastante que desear.

\section{4. - ensayo de dureza}

Es comprensible el deseo de llegar a poder juzgar las condiciones mecánicas (resistencia) de las probetas u objetos de yeso mediante un ensayo sencillo. Se trata de la huella causada por choque o percusión de una bola. La ventaja principal consiste en que el ensayo se efectúa sin destrucción del material; de este modo es posible repetir el ensayo en la misma probeta y a distintos tiempos. Otra ventaja es la sencillez y baratura del aparato empleado, por lo menos comparado con una máquina de ensayo a compresión.

Para el ensayo en el laboratorio tiene ventajas la prueba estática de dureza (huella de la presión de una bola), ya que el aparato puede ajustarse con más exactitud que los de choque o percusión (péndulo de bola). Con el ensayo se determina la dureza Brinell. Para probetas secas se emplea, en general, una bola de acero de diámetro $\mathrm{D}=10 \mathrm{~mm}$ y una sobrecarga de $\mathrm{P}=20 \mathrm{~kg}$. La profundidad $t$ de la huella se mide con una precisión de 1/100 milímetros.

La dureza $H$ se calcula con la fórmula :

$$
\mathrm{H}=\frac{\mathrm{P}}{\pi \text {. D. } \mathrm{t}}=\frac{6.370}{\mathrm{t}} \mathrm{kg} / \mathrm{cm}^{2},
$$

poniendo $D$ en $\mathrm{cm} ; t$ en $1 / 100 \mathrm{~mm}$. La duración de la sobrecarga señalada en DIN 1168 es de 15 segundos. La bola durante el ensayo de probetas bien secas llega tan pronto al equilibrio que, prácticamente, bastan 3 segundos para efectuar el ensayo. Para conseguir un valor medio aceptable, el ensayo suele hacerse sobre tres prismas; en cada uno se hacen 3 huellas.

El ensayo en obra se hace con aparatos de choque o percusión (péndulo de bola) que se transportan con gran facilidad. Nuestras indagaciones sobre la elección de aparatos más adecuados no han terminado aún. Nada definitivo puede darse sobre esta cuestión.

\section{bibliografia}

(1) Albrecht, W.: Yeso de moldeo y enlucido. "Forschritte und Forschungen im Bauwesen", Reihe D, Heft 15. Stuttgart 1953.

(2) Volkart, K.: Estado de la industria y el empleo del yeso en Alemania. "Zement-Kalk-Gips» 17 (1964), cuaderno 6, pág. 252.

(3) WANDSER, B.: La disminución de resistencia del yeso recién fraguado. "Zement-Kalk-Gips» 15 (1962), cuaderno 10, pág. 437. 